\title{
STUDENT QUESTIONING: A COMPONENTIAL ANALYSIS
}

\author{
HANS VAN DER MEIJ \\ TWENTE UNIVERSITY
}

\begin{abstract}
This article reviews the literature on student questioning, organized through a modified version of Dillon's $(1988 \mathrm{a}, 1990)$ componential model of questioning. Special attention is given to the properties of assumptions, questions, and answers. Each of these main elements are the result of certain actions of the questioner, which are described. Within this framework a variety of aspects of questioning are highlighted. One focus of the article is individual differences in question asking. The complex interactions between students' personal characteristics, social factors, and questioning are examined. In addition, a number of important but neglected topics for research are identified. Together, the views that are presented should deepen our understanding of student questioning.
\end{abstract}

The focus of this review is on spontaneous student questioning. Questioning is depicted from start to finish, from the onset of perplexity until the learning that may result. In addition, the characteristic features of questions are described, the assumptions that underlie them, and the answers that follow. Special attention will be given to individual differences in question asking per se and to individual differences in general constructs such as verbal ability and self-esteem that are related to question asking. All of these ideas will be presented within the general framework of the (slightly modified) componential model of questioning of Dillon (1988a, 1990).

This model gives a coherent view on questioning in which the many and diverse studies that relate to student questioning can be placed. That this is not a trivial matter should be clear considering the fact that relevant findings on the topic of student questions can be found in more than a dozen disciplines (e.g., logic, computer science, linguistics, pedagogy and psychology, see Dillon, 1982a, 1986a, 1990), all of which have their own terminology and variety of dependent measures detailing some aspects of questioning.

Another reason for using the componential model was to discover unexplored

Direct all correspondence to: Hans van der Meij, Department of Instructional Technology, Twente University, P.0. Box 217, 7500 AE Enschede, the Netherlands.

Learning and Individual Differences, Volume 6, Number 2, 1994, pages 137-161.

Copyright (c) 1994 by JAI Press, Inc. 
territory. Dillon's model (1988a, 1990) has not (yet) been used as the basis for research on questioning and there was thus a fair chance that the model would help find blind spots. In addition, it seemed likely that the model would yield new insights because it required an integration of various points of view. Thus, the review was also set up in a speculative fashion, aiming to find new and pertinent issues on student questioning.

Clearly then, this is a selective review in which some studies have been left out unintentionally, and others have been ignored intentionally. The article is, for example, not a review on question posing, on the asking of questions that do not originate with the student. The study, therefore, does not review the broad body of research on adjunct questions, nor that on teacher questioning. ${ }^{1}$ The presentation of the componential model of student questioning is preceded by a brief discussion on defining questions.

\section{A COMPONENTIAL ANALYSIS OF QUESTIONING}

Recognizing questions is easy in everyday life. Most people know a question when they hear one. In research, this is not so. Characterizing a question is difficult and most definitions give but a limited view on what asking a question means.

Let us, for example, examine the most prominent one, the linguistic definition. A prototypical example can be found in Webster's dictionary, whose first description of a question is that of "an expression of inquiry that requires or invites an informative reply." In this definition, the aspects form and function merit special attention.

First, the form or expression is usually taken to mean a certain kind of verbal expression. As is emphasized in Webster's second description. A question is "an interrogative sentence or phrase." Typical verbal cues by which questions are distinguished are: the presence of a rising intonation, predicate subject inversion, the presence of interrogatives such as who, why, what, where, and special tags as in the sentence "It is late, isn't it?"

The limitations of this interpretation are obvious to anyone who has ever asked a question nonverbally. Questions can be expressed in many ways other than by words alone. Every parent knows, for example, that children ask many things non-verbally before they can express their desires with words. They raise their hands in order to be picked up, they come towards you with a book making it clear somehow that you should read it to them, and so on.

The second noteworthy aspect of the definition is that of the question's function. A question is meant to elicit a response that can satisfy the questioner. More particularly, Webster's definition refers to an information-seeking purpose by speaking of an inquiry to obtain an informative reply (emphasis added). This function is focal in most of the research on questioning and the questions that serve it are known as real or genuine information-seeking questions.

The limitations of this interpretation too are clear. Questions can serve many 
other purposes than to satisfy a person's curiosity, as in "Can you pass me the sait?" Moreover, they can serve more than one purpose at the same time. Questions may have all sorts of doubles attached to them. For example, a student's questions to the teacher may simultaneously serve to inform, comfort, and motivate.

Its defects notwithstanding, the definition is a useful point of departure for research because it draws the attention to two important dimensions of questions (i.e., form and function), both of which have been the subject of research, as will be shown in the discussion of the componential model.

\section{OVERVIEW}

In various books and papers, Dillon (1982a, 1986a, 1988a, 1990) has integrated insights from a variety of disciplines into a compelling view of what it means when someone asks a question. A slightly modified version of the componential model presented by Dillon $(1988 \mathrm{a}, 1990)$ forms the basis of this review. In this modified model the processes of questioning are linked to their static components. In Dillon's work these views have been presented separately. In addition, Dillon has described the static components to capture mainly question posing, whereas this article deals only with question asking. ${ }^{2}$

Questioning can be described as an ordered event involving three main moments or stages (see Figure 1). The first stage is the onset of questioning. In this stage a person becomes perplexed. That is, a discrepancy between something known and some new information is noted, or the person may encounter an unexpected outcome or find something puzzling. In the second stage a question is developed. The person's perplexity is then transformed into a formulated and expressed question. In the third stage an answer is sought and processed into a new proposition that the questioner now holds to be true. In the left part of Figure 1 the various processes involved in the three stages are described.

Dillon (1990) suggests that there is one static component in each stage that demands the particular attention of researchers. It is a component that can either be observed or inferred. For the onset of questioning the main component is the assumptions of the questioner, the things the questioner takes to be true without proof or demonstration. During the development of the question the main component is the question itself. In the third stage the answer is focal.

Dillon (1990) also suggests that each component should further be subdivided into a sentence and an act to show its logical and pragmatic properties. The sentences reveal what content is communicated in questioning. The acts reveal the motivational and social-communicative aspects involved (see Figure 1).

\section{STAGE 1: THE ONSET OF QUESTIONING}

Questioning can be triggered internally or externally. Perplexity, the resulting moment of this stage, may arise internally. For example, a person may relate 

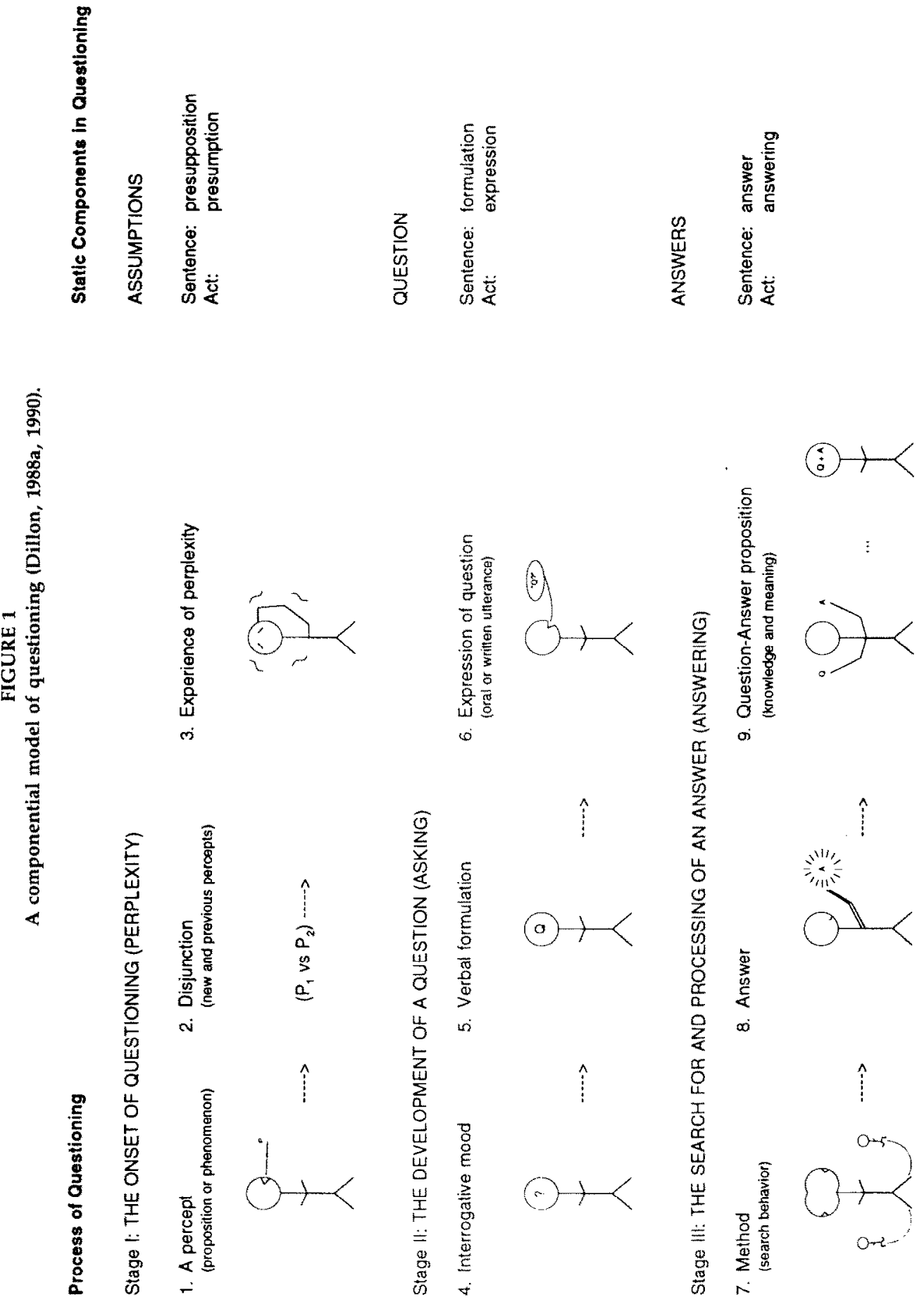
certain known facts to one another and discover that they contradict one another, or his or her reflections may create uncertainty about some previous knowledge. Perplexity can also be triggered by external cues, by events or phenomena in the environment of the questioner (e.g., Berlyne \& Frommer 1966; Garner, Alexander, Gillingham, Kulikowich, \& Brown 1991; Markman 1979; Chinn \& Brewer 1993). For example, a surprising fact or theory presented in a textbook can elicit questioning. In both cases the result is a state of perplexity.

Research on questioning has concentrated on the external conditions for triggering perplexity. It is believed that the most likely condition leading to such a perplexity occurs when a stimulus resembles something well-known but is also distinct enough to be interesting. If it is too remote from experience, or too familiar, the reaction will be one of indifference (Berlyne 1960, 1965; Isaacs 1930; cf. Chinn \& Brewer 1993).

In a slightly different way this idea is echoed in the research hypothesis that question asking frequency is at its peak when prior knowledge is moderate (Miyake \& Norman 1979). When a person has little prior knowledge there is supposedly no foundation for questions to arise. In contrast, when there is much prior knowledge many questions need not be asked as the facts are known or can be inferred. There is by now a wide body of research indicating that this intuitively appealing idea has not been held up in research. Nine out of ten studies find an inverse linear correlation between number of questions and prior knowledge; subjects with less prior knowledge ask more questions (for a review, see Van der Meij 1991 1992). It is, therefore, unfortunate that the frequency hypothesis is still widely cited in the literature. More importantly, it draws away the attention from more interesting issues on student questioning such as the motivations for asking questions, the obstacles to formulating and expressing questions, the difference between internally and externally triggered questioning, and the educational potential of not-answering student questions.

Presuppositions. The presuppositions are all the propositions entailed by the question. Every question contains presuppositions. For example, two presuppositions to the question "Does the Queen of the Netherlands have red hair?" are: (1) there is a Queen of the Netherlands, and (2) the Queen is a person, animal, or thing with hair as an attribute.

It is often in reference to these presuppositions, and the thoughts that spur perplexity, that questions are seen as an important diagnostic, as a window to the mind (see Flammer 1986). And it is to this aspect of questioning that people refer when they stress that questions reveal what a person does not know and what he or she does know.

In order to really understand the question one must get to know its most critical presupposition(s), the one(s) to which the questioner is committed. This knowledge is vitally important not only for understanding the question but also for answering. Galambos and Black (1985) give an illuminating example. Suppose, they say, you hear the following question "Why did Sam eat dinner at the Copper Beach Restaurant?" If you understand the question to be one about 
Sam's motivation for eating, your response might be something like "Because he was hungry." But if you were to understand the question as one about why Sam chose that particular restaurant, your response would be totally different and you might say "He had heard that this was a good restaurant and he wanted to try it." In short, to understand a question, respondents should consider the different meanings implied by the question (e.g., Graesser, Byrne, \& Behrens 1992; Robertson 1993).

Special attention should be given to the truthfulness or validity of the presuppositions (Dillon 1990). For example, when a student asks a question whose presupposition the respondent knows to be false, a cooperative respondent should deal with the presupposition rather than answer the question to avoid saying something that is untrue. In addition, according to Grice's cooperativity maxims, a refutation is also likely to be a more relevant and informative response (see Grice 1975). However, Chinn and Brewer's (1993) review on the role of anomalous data in knowledge acquisition makes one wonder in what conditions refutations do not have the positive effect presumed by Grice's cooperativity maxims. In addition, it is noteworthy that question answering systems in computers appear to have difficulties in handling invalid presuppositions (and other pragmatic issues). For example, questions based on such presuppositions have been called 'misleading' because the system responds to them as if they were true (Robertson, Black, \& Lehnert 1985), or the questioner is assumed to be cooperative, asking his or her question only of someone who can reasonably be expected to share the presupposition(s) (Robertson 1993).

Presumptions. The presumptions relate to the personal motives and beliefs, and to the social-communicative aspects of questioning. Among others they describe certain conditions that the questioner holds to be true. The primary presumption for many question types is that the questioner believes in the truthfulness or validity of the presuppositions. In addition, Dillon (1986a, 1986b) has suggested that a person asking a genuine information-seeking question holds the following eight standard attitudes: ignorance, perplexity, need, desire, commitment, belief, faith, courage, and will (cf. Flammer 1986; Van der Meij 1987).

Surely, the primary presumption is among the more important ones to study. For example, it should be of interest to find out how often students ask questions for which they know the presuppositions to be false (as interrogators do with trick questions). Likewise, it may be worthwhile to examine presuppositions that these students hold to be true only partially, or to study presuppositions they may have flagged as temporarily true (just as researchers flag certain ideas or findings, cf. Rescher 1982). To my knowledge, research on student questioning has given little to no attention to these issues.

In addition, it would be valuable to know how often Dillon's (1990) standard presumptions are true for student questions in classrooms. There is some research suggesting that the frequency of information-seeking questions may be significantly lower than the already alarmingly low overall frequency of student questions. For example, researchers have sometimes qualified a student's questioning as executive and excessive (as opposed to instrumental) to signal a depar- 
ture from the standard attitudes. Students showing these kinds of questioning behavior do not exhibit need, will, or desire to learn from the response they receive. Instead, it is their intention to have the teacher or respondent solve the problem on their behalf, to rid themselves of the unpleasant state of ignorance (e.g., Aberbach \& Lynch 1991; Nelson-LeGall 1985; Nelson-LeGall \& Glor-Scheib 1985).

There is also some evidence for the non-information-seeking background of student questions from a within classroom experiment that two students and I conducted. In that study, students were given a lesson that seemed like a regular lesson, but for the fact that the individual assignments were tasks that they already knew how to solve ( $95 \%$ correct on similar problems given in a lesson three days earlier, Van der Meij, Meer, \& Ponte 1989). We expected a small decline in information-seeking questions which would indicate that some of these questions, typically formulated as "I don't know this," would not stem from a genuine need for information. To our surprise, a significant increase of the number of questions asked was observed. In fact, there were almost twice as many information-seeking questions. When we further examined this outcome we found that the best predictor of the students' behavior during the experiment was their question-asking frequency during regular lessons. That is, a student who would ask but one or two questions during regular lessons would do so also during the experimental lesson and so on. We took this to suggest that some of the questions these students regularly ask only resemble true informationseeking questions; they are probably not primarily be intended to find necessary or missing information.

Social norms can also affect questioning, of course. There has been a considerable debate whether student question asking is a signal of dependency and should be discouraged most of the time, or whether it really signals independence and should be encouraged most of the time. Authors such as NelsonLeGall (1985) and Newman (1992), who support the latter view, argue that questioning is an adaptive action of the student helping him or her to regulate learning. Even the students themselves express some ambiguity on this matter, and factors such as their age, the type of helper, and work situation have been found to affect their concerns with being or becoming independent (e.g., Newman \& Goldin 1990; Van der Meij 1988).

There is also a fair body of research suggesting that certain personal characteristics of students significantly affect their questioning. The ones that have been studied most intensively here are achievement, achievement motivation, and self-esteem (e.g., Good, Slavings, Harel, \& Emerson 1987; Nadler 1983; Nelson-LeGall 1985; Newman 1992; Shell \& Eisenberg 1992; Van der Meij 1990b). For example, Good's passivity theory suggests that low achieving students have learned to become less involved in schoolwork, to become non-question askers. Ihis, the theory suggests, is a reaction to the negative responses these students usually receive to their behavior in classrooms. Thus, whereas low achievers begin school asking as many questions as their peers, they come to ask fewer questions during their school period.

In a broad survey on question asking in school this prediction was substanti- 
ated and interactions with school and age were found (Good, Slavings, Hobson, Harel, \& Emerson 1987; Good, Slavings, \& Mason 1988). In addition, the researchers suggested that good questioning skills of students and positive teacher reactions may reinforce one another, leading to a favorable atmosphere for student questioning. In contrast, when students do not express their questions very well teachers may structure their classroom to avoid problems. That is, when students ask vague questions, when they pose questions at the wrong time, or for the wrong purpose (e.g., to avoid listening), teachers may react by imposing restrictive rules (Good et al. 1988).

It is also possible that the various personal characteristics needed for questioning work against one another, and, indeed, that a single characteristic (e.g., selfesteem) stimulates perplexity and obstructs the expression of a question. Un fortunately, there is little research on this matter because studies on student questioning often do not distinguish between the first two stages of questioning. That is, they study only the presence or absence of a question being asked.

This may be an important neglect. It is quite likely that the effects of personal characteristics such as ability, achievement, and self-esteem differ for these two stages. For example, in one study I found that low self-esteem students indicated significantly higher levels of perplexity (i.e., uncertainty) but this did not lead to the expression of more questions (Van der Meij 1989). Because self-esteem, ability, and achievement tend to be positively correlated to one another, one explanation for this finding may be that the positive effects of one characteristic (e.g., low self-esteem) on the onset of questioning are weakened by the effects of another characteristic (e.g., low verbal ability) needed to support the formulation of a question. An alternative explanation would be that self-esteem alone might account for the result, because, according to the vulnerability hypothesis (see Nadler 1983), a person with a low self-esteem is especially prone to protect his or her self-image and hence will be hindered in posing questions.

Finally, it is likely that the motives for asking a question may stem from a combination of needs rather than just a single purpose. That is, even when students ask questions primarily to seek necessary information, secondary motives such as a need for emotional support or for social companionship may be attached to these questions (cf. Evers \& Westgeest-DeGraaf 1989; Newman 1992; Van der Meij, Meer, \& Ponte 1989). In addition, students might also use their questioning as an impression management tactic, as a means to create a favorable impression on others (cf. Fuhrer 1989). These various goals may affect the formulation and expression of questions and the responses given to them.

\section{STAGE 2: THE DEVELOPMENT OF A QUESTION}

In the second stage the student must come to grips with what perplexes and make it more tangible. The student must articulate and express the problem or perplexity. Whereas this articulation may take place almost simultaneously with perplexity, this is not necessarily the case. In fact, it is quite likely that the 
transition from perplexity to the formulation and expression of a question is a most difficult process.

The difference between being perplexed and framing a question can perhaps best be illustrated by comparing it to the subtle difference between problem finding and problem formulation. Whereas the first refers to finding the problem area, it is only the second that enables the person to start a creative attack to the problem (Dillon 1982b; Getzels 1982, 1988; Subotnik \& Moore 1988; cf. Paradice 1992).

It is this stage to which one can allocate research concerning the kinds of questions people ask. Surely the research on the development of children's questions has been among the most influential in this respect. Not only does this research indicate when certain questions first emerge, such as when children begin asking questions that inquire after the causes of things, but also how these questions should be interpreted (e.g., initially as 'maids of all work', Piaget 1959) and how the environment responds to them (e.g., Callanan \& Oakes 1992; Tizard \& Hughes 1984; Vygotksij 1962).

To this stage also belong the various typologies on questions. These typologies typically serve both to diagnose the meaning and origin of questions and to structure the respondents' actions. For example, computer scientists often use a typology of questions to identify classes of question structures (i.e., question categories) that, in turn, improve the chances of generating a response that satisfies the request of the questioner (e.g., Graesser, Byrne, \& Behrens 1992; Hartley \& Smith 1988; Lehnert 1978; Pilkington 1992; Robertson, Weber, Ullman, \& Mehta 1993).

Formulation. In formulation the questioner invents the logical or conceptual units of the question and relates these units to one another. In simple terms, the person must find the right words and structure for the question (cf. Allen 1987; Dillon 1990). This is the stage for studies into the "what" of people's questions.

The difficulty in formulating questions has been studied in research comparing question selection with question generation. In the selection condition students can choose what question(s) they want to ask from a prearranged set. They have, so to speak, their question(s) prepared for them. In the generation condition students must formulate the question(s) themselves.

Among others, these comparisons suggest that formulation poses formidable barriers to questioning and that verbal ability strongly affects this phase of questioning (Van der Meij 1990a, 1990b, 1990c). For example, fifth-graders with low verbal ability were found to have severe problems with formulating questions to find the meaning of a word (Van der Meij 1990b; Van der Meij \& Dillon in press). One of their problems resided in formulating a question altogether. That is, some of these students were observed to start with the stem of a question, fail to frame a question, and then give up, asking nothing at all. Another problem was noted in the questions these students did express. In general, these questions were not very discriminative (e.g. "Does imitate have something to do with doing something") or they added little to what was already given 
(e.g., "Has estimation something to do with estimate?"). In contrast, students with high verbal ability more often came up with their own thoughts about the target words and formulated sharper questions (e.g., "Has estimation something to do with making a guess?").

In question selection studies manipulation checks are necessary to exclude the possibility that the presentation of ready (i.e.. formulated) questions affects the onset of questions (i.e., perplexity). In most studies that try to stimulate student questioning (for reviews see Wong 1985; Rosenshine \& Chapman 1992) there is no such control and it cannot be determined whether students are prompted to wonder about things, or whether they are helped to articulate their perplexity.

The formulation problem is also widely recognized in the computer industry where various attempts have been made to create user-friendly point and query devices to alleviate it (e.g., Lang, Graesser, Dumais, \& Kilman 1992; Schank 1993). Interestingly, here too people are given a set of questions from which to choose. But here, instead of a mere means to study the problems of formulating questions, the selection procedure is turned into a useful tool for stimulating questioning.

Another interesting view on the formulation problem is presented by Chinn and Brewer (1993) who describe the various ways in which science students react when confronted with a perplexing fact (i.e., anomolous data). Among others, these authors suggest that students sometimes cope with their perplexity by ignoring, rejecting or holding in abeyance certain data. In addition, some perplexities may prompt certain types of questions or hypotheses and lead to the design of critical experiments that can confirm or disconfirm the validity of the data.

With regard to the question's structure, one of the most salient factors in research is the openness of questions. At one end of this dimension one finds questions that include their own answer (e.g., rhetorical questions). At the other end one finds questions for which any response would appear to qualify as an answer. Here one might think of single worded expressions like "Huh?" and "Uh?" as examples. In experiments, the questions studied are somewhat less extreme than the above examples, but they still differ widely. The dominant type of closed question studied is the one that can be answered by a "Yes," a "No," a "Maybe," or a "Don't know." In contrast, there is no dominant type of open question because, by their very nature, these questions hardly cue the answerer, the answers are more open.

Provocative research in this area includes studies that compare the effects of external and internal stimuli on the quality of student questions. The scarce investigations on this topic strongly suggest that questioning that is prompted by the person's own reflections leads to deeper, more fundamental questions than questioning that is prompted by external factors such as the textbook or teacher (Bereiter \& Scardamalia 1992; Scardamalia \& Bereiter 1991, 1992; cf. Brown 1992; Fishbein, Van Leeuwen, \& Langmeyer 1992; King 1992; Van der Meij 1993; Van Zee \& Minstrell 1991, 1993).

Yet another salient type of research addresses questions asked in a series, 
where a following query is contingent in some ways on a previous question and its answer. There are many situations in which a single question can best be comprehended by looking at the series of questions from which it forms a part. I here are at least two related, and yet distinct, lines of research on such strategic questioning: questioning to solve problems, and questioning to learn how to do something. Each of these approaches will be described below.

One line of research on strategic questioning concentrates on questioning to solve abstract problems. In general, this research centers around how well subjects succeed in narrowing down the number of afternative solutions through their questions. Among others, this issue has been studied extensively in the twenty-questions game. In this game, originally a parlor game dating from the late nineteenth century, students can ask yes/no questions in order to guess an object. The goal is to solve a problem using as few questions as possible.

The two main strategies that are generally found are hypothesis testing and constraint seeking (Mosher \& Hornsby 1968). That is, in order to solve the problem "I have a blue object in mind," a hypothesis tester would typically ask questions like "Is it your eyes?", "Is it the sky?" or "Is it that pencil over there?". In contrast, a constraint seeker might ask "Is it in this room?", "Is it animate?", "Can it move?" and so on. Constraint seeking is less direct, but more strategic and more efficient than hypothesis testing.

The questioning in the game was also linked to the domain at hand. That is, students tended to ask several questions about one domain before asking questions about another (e.g., Siegler 1977; Van der Meij 1986; cf. Schraagen 1993). In order to find the cause of a car accident they would, for example, first ask various questions about the driver as a possible cause (e.g. "Did the driver cause it?", "Was the driver not careful?", "Was he drunk?"), before asking questions about other possible causes such as external circumstances or defects to the car. This fits well with the more general observation that questioners tend to explore facets of a category (or slots in a schema) before rejecting a category or specializing search within a facet.

In general, the search strategies have been found to depend on both the age of the questioner and the stage of the game (Siegler 1977; Van der Meij 1986). Not surprisingly, constraint seeking tends to increase with age. Older students more often follow a constraint seeking approach than younger ones. In addition, questioning is often more strategic at the beginning of the game; the first questions exclude more options than later questions.

The second line of studies on strategic questioning focuses on the questions people ask when they learn how to do something. This research has aimed to study the effects of schemata and scripts on a person's questioning, and attention is given to the asking of generalizable, higher-order (and yet domainrelated) questions. For example, investigators have examined whether subjects ask questions about goal states, about solution methods, necessary materials, end states and so on.

Notable research on this matter comes from Flammer and his colleagues (Flammer 1986; Flammer, Grob, Leuthardt, \& Lüthi 1982a, 1982b, 1984; Flammer, 
Kaiser, \& Lüthi 1981; Flammer, Kaiser, \& Müller-Bouquet 1981; cf. Letovksy 1986). In the Flammer et al. (1984) experiment, subjects had to prepare a "mousse au chocolat" after having been allowed to ask all information they felt would be necessary. The results showed that the subjects did not follow the recipe-making script very closely, but an interaction between prior knowledge and the dominance of certain question types was found. Subjects with more cooking knowledge asked more higher-order questions. That is, their questions more often dealt with the organizational aspects of the task and with goal and end states. In general, this positive effect of prior knowledge on the asking of higher-order questions has also been observed in a variety of other studies (e.g., Fuhrer 1989; Scardamalia \& Bereiter 1992; Schraagen 1993).

From the latter type of research it is only a small step to the study of the sequencing of particular questions. In questioning research little research is conducted on this matter. One of the topics that seems worthwhile to examine is whether the question types in various stages of learning differ in a predictable way. For example, one might expect that goal formation and plan questions appear mainly at the beginning learning stage, information processing, act and regulative questions in the middle, and evaluative questions at the end (cf. Kato 1986; Robertson \& Swartz 1988; Schraagen 1993; Smith, Tykodi, \& Mynatt 1988).

Alternatively, one might also want to consider characterizing questions according to their support for tuning, accretion, and restructuring activities in learning (cf. Miyake 1986). In conducting such research it will be important to allow questioning during learning rather than only in advance of it. Because such a procedure affects questioning it will be important to pay special attention to controllability.

How can the researcher make sure that all respondents are treated in the same manner? On this matter the Flammer studies are again exemplary, suggesting the need for a complete scenario covering task content, question typing and response strategies (cf. Van der Meij 1992).

In general, questioning research has paid little attention to the overall purposes for which information-seeking questions are being asked. In this respect one might consider following a distinction that has been made in reading. That is, it may be helpful to distinguish between questioning to gain knowledge (to understand), questioning to do (to act), and questioning to locate information (to search). Each of these purposes may have its distinct effects on questioning and may affect what should be studied in questioning. As related above, questioning should perhaps also be linked to the various stages and processes in learning.

Expression. This term refers to the act of putting the question into words. Questions vary widely with regard to how they are expressed and which characteristics of the questioner they reveal. In many classrooms, however, questioning is bound to rules students must obey. In most cases these rules, which are meant to regulate the interactions, obstruct questioning. For example, teachers often impose rules on the frequency and nature of student-student interactions. In addition, explicit and implicit rules often regulate the interactions between stu- 
dents and teachers (Van der Meij 1988). These rules make posing a question in the classroom a highly conspicuous affair (e.g., during instruction questions must be signaled by raising a hand and during seatwork the student must walk up to the teacher's desk at the front of the classroom), and frequently students verbally and nonverbally show their deference to the teacher in their questions.

Many students even appear to be afraid to pose the questions they have in mind, leading Dillon to the suggestion that the last move in this stage, the expression of the question, is the most difficult to take. "Fully 95 per cent of the questions that we have in mind to ask we never go on to utter. As before, we may think the better of it and follow one of the numerous other paths available. These include keeping quiet and giving off that we know and understand" (Dillon 1988a, p. 20). The most important issue to consider with regard to expressing a question, therefore, concerns the factors that cause questions to be dissolved or that block their expression. These causes vary, of course. Personal but also social-normative factors are operative.

The expression of questions in the classroom often seems to be blocked by contextual factors. Students are afraid to pose their questions because of a fear of being shamed for asking a stupid question, a desire not to impose on the teachers' time, or the belief in some rule of conduct prohibiting the asking at that time (e.g., Karabenick 1991; Karabenick \& Knapp 1988; Karabenick \& Sharma 1991; Newman 1992; Van der Meij 1988, 1990b). For example, asking a question in large group settings is much more difficult than asking the same question in small groups or to individuals (cf. Fuhrer 1989). It is not that people have no question to ask. It is only the condition which is so unfavorable for the asking, or so it seems. Indeed, most lecturers and teachers probably know some students who never ask questions in class, but often come to them with questions after the lesson is over. Not the formulation of a question is blocked, only its expression, its coming out into the open. In classrooms the social-normative obstacles to questioning are very high; teacher and textbook questioning is the norm.

The expression of questions can also be blocked by personal factors such as achievement motivation and self esteem (e.g., Nadler 1983; Newman 1992; Shell \& Eisenberg 1992). For example, it is assumed that a person's self-esteem affects that person's perception of the benefits and costs attached to questioning (Shell \& Eisenberg 1992). In observations and experiments with fifth-graders, my students and I have found some effects of self-esteem on questioning that support the consistency view. That is, high self-esteem students seem particularly sensitive to the costs of asking questions and therefore refrain from expressing them (Evers \& Westgeest-DeGraaf 1989; Van der Meij, Baarends, \& Leijh 1988). It should be noted, however, that we have also conducted a number of studies in which no effects of self-esteem were found (Schouten \& Zwijnenburg 1987; Van der Meij, Meer, \& Ponte 1989; Van der Meij 1989, 1990a, 1990b). In all, these studies support the idea of a complex interaction between this personal factor and other factors such as the consequences to self, the amount of control by the students, and the stage of questioning studied.

There may, for example, be an interesting connection between what happens 
after perplexity and a student's volition (cf. Corno 1993). Corno suggests that, whereas motivation plays an important role in perplexity, volition becomes more important after perplexity, where it may help students manage and implement goals and actions that lead to the development of a question. Among others, volition may be vitally important for contingent queries, helping students fend off distractions from their search strategies.

Occasionally, a student may decide to frame the question differently or to pose another question for social reasons. For example, the questioner may begin with a foot-in-the door question in order to introduce the real question. Students may, for example, carefully construct a persuasive appeal, or ask a simple "May I ask you something?" One could speculate that this explains why, even during seatwork, a student's initial utterance in contacting their teacher is often an open question such as "I don't know this" and "Can you help me?" It is because students follow a code of politesse to moderate their chances of getting a negative response; they know they must persuade the other to respond favorably (cf. Dillon 1988a, 1990; Nelson-LeGall 1985). In order to find out whether students ask these open questions because of social factors, or because they lack the skills to formulate closed questions, it will be necessary to manipulate the predisposition to cooperate. When cooperation is made a non-issue, open questions probably signal lack of skill.

Finally, a student may also frame the question differently for communicative reasons, to accommodate the respondent. Questioners (and respondents) must be concerned with creating a common ground (Gibbs, Mueller, \& Cox 1988). For example, asking whether one's brother can be considered stout may reflect a wonderful typing of stoutness, but it is incomprehensible if the respondent does not share some knowledge about the questioners' brother.

\section{STAGE 3: ANSWERING}

Answering consists of a search for information, the finding of an answer, and its processing. Clearly, there are many ways of obtaining an answer. A questioner may find an answer through direct retrieval in memory, or by conducting a plausibility analysis leading to an inferred answer (for a detailed description of such processes, see Reder 1987). Most of the research on student questioning does not deal with these internal processes, however, but concentrates on the questions asked of other sources, personal or non-personal.

Two interesting lines of research on the study of non-personal help sources will be mentioned here. The first is the recent research falling under the rubric of search behavior. The second is the work of Scardamalia and Bereiter on a Computer-Supported Intentional Learning Environment (CSILE). Each of these approaches is described below.

Research on search behavior focuses on the strategic inquiry behavior of students who wish to locate specific information in a book or computer (e.g., Byrnes \& Guthrie 1992; Dreher 1993; Dreher \& Brown 1993; Dreher \& Guthrie 1990; Guthrie \& Dreher 1990; Yussen, Stright, \& Payne 1993). This research shows how students find (and often don't find) their way through accessing aids 
such as indexes, tables of content, glossaries, and headings to the right place in the body text.

Finding the correct location appears to be especially difficult when the right information is to be found in different places of a document. For example, in one study it was found that only about fifty percent of the high school students succeeded in finding an answer to a question requiring the integration of information from three different locations (Dreher \& Guthrie 1990). In general, the studies show that students' search strategies are positively affected when the students know the architecture of the system (e.g., book or database) or when they possess some knowledge of the topic for which they search information. Recently, the goal formation component in this search behavior (i.e., the formulation problem) has become a topic of research (Dreher \& Brown 1993).

The research of Scardamalia and Bereiter on CSILE has an even broader perspective as it focuses on the design of an environment in which students are stimulated to pursue finding an answer to their own questions. The main idea in CSILE is to move away from an attention to tasks and activities towards knowledge-building, to making the students responsible agents in learning (Bereiter \& Scardamalia 1992; Scardamalia \& Bereiter 1991, 1992, 1993).

Among others, the authors suggest making answering the shared responsibility of all the people in the classroom. In one CSILE classroom answering has thus become a collaborative effort to which many students and the teacher contribute. This is made technically possible through the communal nature of the database, joint plannings, bulletin board and mail facilities, but the core issue is, of course, the adoption of a collaborative knowledge-building philosophy (Bereiter \& Scardamalia 1992, 1993).

In general, when questions are posed to other people there is a fair chance that no answer is given because the very least people do is give an answer. Most replies are non-answers, "more or less responsive noises following a question" (Belnap \& Steel 1976; cf. Harrah 1984). Instead of speaking of answers and answering, Dillon (1990) therefore prefers to address the sentence part as response, and the act as responding.

When and how answers should be given is an issue that has been treated in detail in philosophy and by computer scientists (e.g. . Graesser, Byrne, \& Behrens 1992; Harrah 1984; Lehnert 1978; Pilkington 1992). Only some of the general issues involved will be discussed. Special attention will be given to answering student questions because, compared to the gencral case, additional, and even completely different considerations are at stake. Among others, a distinction is called for between responses that promote independence and responses that promote dependency (Shell \& Eisenberg 1992; cf. Dillon 1988a, 1988b).

Answer. A cooperative respondent replies with a response that is relevant, informative, comprehensible, and true (Grice 1975). What counts as an answer can be determined only by the questioner, however. Only the questioner can decide whether the question has been answered. In addition, it should also result in what Dillon calls learning. The student must 'do' something with the response.

Among others, this means that one must go beyond registering the mere 
reception of a response as the end state of an inquiry (cf. Nelson-LeGall 1981; Nelson-LeGall \& Glor-Scheib 1985; Newman 1992). To my knowledge there are no studies that have looked deeply into the matter of answerhood in relation to student questioning in the classroom. Conducting such research would probably require an ethnographic approach. Individual students should be followed when they (are about to) ask questions, their questions must be recorded, and so should their teachers' responses. Good responses (i.e., answers) could then be operationalized by looking at whether the questioner is able to solve similar problems afterwards. Such research might show the success rate of interactions between students and teachers and the factors that affect such successes.

The processing of a response to one's question can be as problematic as that of raising and posing questions in the first place; students' processing of responses is often inadequate (Van der Meij 1990b; Van der Meij \& Dillon in press). For example, when fifth-graders began asking questions to find the causes of a car accident they would often start with a higher-order question like "Did the driver cause the accident?" In theory, this is a strategic question because a "Yes" or a "No" response enables the exclusion of a large number of alternatives. In practice, however, many students did not benefit from asking such a question because, after a "No", they would frequently ask another, lower-level question questions bearing on the same type of cause (e.g., "Was the driver not careful?" Van der Meij 1986). Apparently they found the processing of responses so difficult, that even for this clear question and response they failed. Why do students fail to process the responses to their own questions?

From the descriptions given earlier, it should be clear that the causes can be conceptual, social, or motivational and that they may lie in the first, second, or third stage of questioning. For example, it is possible that the student does not fully grasp the implications of the question. In other words, the student may not really know how good or strategic his or her question really is. Its qualities may dawn on the student only after the reception of the response. Another explanation would be that the response contains unexpected information, continuing the student's perplexity. This might show up in a follow-up question signalling disbelief (e.g., "Is it truly not . . . ?"). Of course, it is also always possible that the questioner has not even heard the response, or that he or she is not truly interested in getting an answer. Another explanation altogether is that the student does find the response inadequate but does not dare to admit so, or finds it improper to ask another question. In short, response processing can be deficient for a variety of reasons argued for in the componential model (cf. Chinn \& Brewer 1993).

In experimental research on student questioning the notion of instrumentality has been introduced as a way to indicate how well students process responses (Van der Meij 1990a, 1990b). Instrumentality is a rubric for questioning that can be helpful or harmful. When a response helps the student find the correct answer to a problem it is called helpful. In contrast, harmfulness signals a negative effect of questioning. It shows a shift from a correct conception into an incorrect one. A simple example can perhaps best explain these two aspects of 
instrumentality. Suppose that two students are asked about the meaning of the word deliberation. Student A wrongly believes the word means freedom; student B rightly believes that it means reflection. Both students ask one or more questions. When student $A$ then changes his or her answer into 'reflection', questioning is defined as helpful; when student B changes his or her answer, questioning is considered to have been harmful.

It is difficult to measure instrumentality, even in experiments, because of all the controls that must be brought in. For example, it is important to ascertain that failures cannot be blamed on the respondent. The respondent must understand the question, he or she should know the referent(s) of the question. This problem can be solved by presenting students with a set of alternatives, of which one is the correct answer. This answer sets helps create a common ground between questioner and respondent in which the referent(s) of the question can be traced with reasonable accuracy. To know whether questioning is helpful or harmful one should, of course, also find out whether the student already knows the answer. For this, tentative or provisional answers can be requested before questioning. They indicate the student's best guess. If, furthermore, the researcher is interested only in response processing and not in the combination of questions and answers, it will be necessary to control for the qualities of the questions that are posed. By using a selection procedure such control is possible and the outcomes can truly be ascribed to better response processing. Of course, it will also be necessary to correct for chance to get a fair estimate of the instrumentality of student questions.

In general, research has indicated that instrumentality is positively affected by the student's verbal ability. Students with high verbal abilities process responses better. That is, their questioning tends to be more helpful and less harmful (Van der Meij 1990a, 1990b).

Answering. With the possible exception of Dillon's work, little is known about answering student questions. Answering these questions is a different matter than responding to a question per se, because the respondent (i.e., teacher) should also take pedagogical issues into consideration (e.g., Dillon 1986a, 1986b, 1988a, 1988b, 1991). Among others the teacher might want to respond so that the student's inquiry is sustained and take the possibility of stimulating independence into consideration. How, then, should student questions be answered, and how well are they being answered?

According to Dillon (1988a 1991), the last thing to do is to answer the question. Teachers, he suggests, should sustain the asking, "even if the question concerns 1066 and all that" (Dillon 1988a, p. 30). To sustain the asking Dillon advances five general ways: (1) reinforce and reward the experience of perplexity and expression of inquiry, (2) help the student and classmates to devise a method to address the question, (3) find out the question that the student has in mind to ask, (4) examine together the grounds of the question, and (5) appreciate the student's state of knowledge revealed by the question. Only at a later time may the teacher find it appropriate to answer the question. These suggestions of 
Dillon differ slightly from those of Scardamalia and Bereiter $(1992,1993)$ for CSILE, but the main idea is the same. Teachers should create an environment that stimulates inquiry and knowledge building (cf. Van Zee \& Minstrell 1991, 1993).

The guidelines for responding to student questions in experimental studies do not stem from such a pedagogical perspective (and often rightly so). To my knowledge, only Flammer and his colleagues have developed a detailed scenario for giving the "right" responses (see Flammer, Kaiser, \& Lüthi 1981; cf Graesser, Byrne \& Behrens 1992). According to Flammer, respondents require knowledge about the following factors. First, they need domain or task-specific knowledge. Second, they must know how to classify the questions. Third, they must have a set of principles for selecting the right response.

In his experiments, especially in the later ones, Flammer worked hard to standardize these factors. So he began drawing a detailed chart of the experimental task (i.e., preparing a "mousse-au-chocolat") and presented this chart to the respondents who then all shared the same domain knowledge. Next he categorized the domain into a number of classes (e.g., goals, actions, criteria for success, ingredients, and instruments). For each class he then specified the kinds of questions into types (e.g., yes/no, global/specific, one or more steps) and coupled each to a specific response rule. For example, if a subject asked a question like "What do I use for mixing?" all respondents would classify the question as one about instruments and type it as global. Following their response rules they would then answer "with a rod." Interestingly, Flammer (1986) later argued that he found himself tangled in issues concerning question answering rather than in question asking in which he was interested.

\section{CONCLUSION}

Questioning in school has been equated with teacher or textbook questioning. One of the arguments given in support of these practices is that it serves as a model, that students will imitate these questions, and that it helps them to further develop their questioning skills. To some degree this hypothesis has been validated in research. But, unfortunately, teachers and textbooks often ask simple fact questions. Only rarely do they ask questions that they are really interested in. And so, by consequence (?), do students in school.

How can this condition be improved? For some, the answer lies in improving the questioning of teachers and textbooks, in raising the level of their questions. This will surely improve student questioning, but there are at least two reasons why this may not help enough. One, it does not give students enough chances to ask questions. When the teacher or textbook asks there is no room for student questions. Two, it is doubtful whether teachers or textbooks can act as substitute questioners. That is, whether they can ask information-seeking questions that are (according to the teacher they should be) of interest to students. The questions of fellow students are better candidates, but they too cannot substitute 
because what perplexes is intimately bound to the questioner, to his or her knowledge, interests, beliefs and so on (cf. Ross \& Balzer 1975; Ross \& Killey 1977).

More fundamentally, one might ask how some questions come to be appropriated by students. How is it possible that students adopt questions that do not originate with themselves? Is it merely a signal that students learn how to play the academic game, a game that resolves around teacher questions and student answers? Or, more optimistically, do students adopt those questions and questioning techniques that have a clear value to them? For example, students may adopt a strategy of asking metacognitive questions because they find it a valuable technique for regulating their learning. ${ }^{3}$

For these learned questioning strategies it is important to consider their stability. For example, it is important to know whether these techniques are maintained over a long period of time and if they are maintained after supporting conditions are removed. In short, the topic of student appropriation of questions is an important topic for research on student questioning in which some pertinent topics are yet to be addressed.

An alternative point of view altogether would be to start from the student's own questions, that is, to give students the opportunity to work on their own questions for some time during the day, say half an hour to an hour. Would this help students ask more and better questions? The research of Bereiter and Scardamalia suggests that it does when certain conditions are fulfilled. For example, it will be necessary to provide for public and private displays of their work in progress, for access and interchange of texts, notes, source materials and so on. In addition, there should be time for reflection and refinement (Scardamalia \& Bereiter 1993).

Under the right conditions, students ask questions that "have the potential to lead to significant advances in understanding" (Bereiter \& Scardamalia 1992, p. 232). They show themselves capable of conducting a progressive inquiry in ways that are similar to those of scientists (cf. Chinn \& Brewer 1993). What this research has hardly detailed yet is how students' questioning skills develop. When student questioning is going to be given a bigger role in education, it will be helpful to understand better the processes of questioning.

The present article has tried to accomplish just that. Among others, it has been emphasized that favorable social conditions are important for student questioning. It has also been emphasized that certain personal factors are vital. Questioning often is a very personal affair. It is intimately bound to a student's prior knowledge and skills, and to his or her motivation and volition. Further research on these social and personal factors in questioning may yield fundamental insights for redesigning their learning environments, helping students cope better with the information overflow in school and at home.

ACKNOWLEDGEMENTS: The author wishes to thank the reviewers F.N. Dempster, P.H. Winne and, especially, T.M. McDevitt for detailed comments on the first draft of this article. Special thanks go to J.T. Dillon for comments on a first draft and for continued support and stimulation. 


\section{NOTES}

1. Some authors (and research) suggest that adjunct and teacher questions positively affect student questions; others argue that their effect on student questioning is minimal and can never substitute for the students' own, spontaneous questions. By way of argument for the latter position one might point out that it seems strange that someone should have to teach students to start questions with 'who', 'where', 'why' etc. when children as young as 4 years of age have been observed to ask an average of 26 questions per hour (Tizard \& Hughes 1984). At the least, this suggests that the context in which children are being urged to ask questions is not one that activates their full complement of cognitive resources (cf. Scardamalia \& Bereiter 1992). By way of counter-argument one could also argue that students still need to learn how to ask questions that support learning. For example, they can learn how to improve their study strategies by elaborative interrogations. That is, by asking more questions such as "What do I know about this word?", "How can I find out?", "Is this the right approach?", or "Why does this make sense?" (e.g., Pressley \& Forrest-Pressley 1985; Woloshyn, Pressley, \& Schneider 1992).

2. Some of these descriptions and most of the research issues that are linked to this model, stem from the present author. They are not necessarily implied by Dillon's original model.

3. Scardamalia and Bereiter's conception of collaborative answering also assumes an adoption of questions.

\section{REFERENCES}

Aberbach, A.J. \& S. Lynch. (1991, April). Factors influencing children's help-seeking styles. Paper presented at the annual meeting of the American Educational Research Association, Chicago.

Allen, J. (1987. Natural language understanding. Menlo Park, CA: Benjamin Cummings Publishing.

Belnap, N.D. \&. T.B. Steel. (1976). The logic of questions and answers. New Haven: Yale University Press.

Bereiter, C. \& M. Scardamalia. (1992). "Two models of classroom learning using a communal database." Pp. 229-241 in Instructional models in computer-based learning environments, edited by S. Dijkstra, H.P.M. Krammer \& J.J.G. van Merriënboer. Berlin: Springer.

Berlyne, D.E. (1960). Conflict arousal and curiosity. New York: MacGraw Hill. (1965). Structure and direction in thinking. New York: Wiley.

Berlyne, D.E. \& F.D. Frommer. (1966). "Some determinants of the incidence and content of children's questions." Child Development, 37, 177-189.

Brown, A.L. (1992). "Design experiments: Theoretical and methodological challenges in creating complex interventions in classroom settings." The Journal of the Learning Sciences, 2(2), 141-178.

Byrnes, J.P. \& J.T. Guthrie. (1992). "Prior conceptual knowledge and textbook search." Contemporary Educational Psychology, 17, 8-29.

Callanan, M.A. \& L.M. Oakes. (1992). Preschoolers' questions and parents' explanations: Causal thinking in everyday activity." Cognitive Development, 7, 213-233. 
Chinn, C.A. \& W.F. Brewer. (1993). "The role of anomalous data in knowledge acquisition: A theoretical framework and implications for science instruction." Review of Educational Research, 63(1), 1-49.

Corno, L. (1993). "The best-laid plans. Modern conceptions of volition and educational research." Educational Researcher, 22(2), 14-22.

Dreher, M.J. (1993). "Reading to locate information: Societal and educational perspectives." Contemporary Educalional Psychology, 18, 129-138.

Dreher, M.J. \& R.F. Brown. (1993). "Planning prompts and indexed terms in textbook search tasks." Journal of Educational Psychology, F85, 662-669.

Dreher, M.J. \& J.T. Guthrie (1990). "Cognitive processes in textbook chapter search tasks." Reading Research Quarterly, 25, 323-339.

Dillon, J.T. (1982a). "The multidisciplinary study of questioning." Journal of Educational Psychology, 74, 147-165.

- (1982b). "Problem finding and solving." Journal of Creative Behavior, 16, 97-111. . (1986a). "Questioning." Pp. 95-127 in A handbook of communication skills edited by

O. Hargie. London: Croom Helm.

- (1986b). "Student questions and individual learning." Educational Theory, 36, 333341.

. (1988a). Questioning and teaching: a manual of practice. New York: Teachers College. (1988b). "The remedial status of student questioning." Journal of Curriculum Studies, 20, 197-210.

. (1990). The practice of questioning. New York: Routledge.

. (1991). "Questioning the use of questions." Journal of Educational Psychology, 83, $163-164$.

Evers, C.C.A.G. \& Westgeest-DeGraaf (1989). To ask or not to ask, that's the question: An exploratory study into the relationships between personal characteristics and question asking in the classroom. Unpublished master's thesis, Leiden University, Leiden, the Netherlands.

Fishbein, H.D., R. Van Leeuwen, \& D. Langmeyer. (1992). "Teacher versus learner controlled instruction: question-asking and comprehension." British Journal of Educational Psychology, 62, 126-131.

Flammer, A. (1986, May). Asking a question: which one-if any? Paper presented at the Memphis conference on question generation. Memphis, Tennessee.

Flammer, A., A. Grob, T. Leuthardt, \& R. Lüthi. (1982a). Wissen zum Fragen und Fragen nach Wissen [Knowing to ask and asking to know] (Internal Report No. 28). Fribourg: University of Fribourg.

___. (1982b). Zur Sicherheit: Frag doch! [To make sure: Ask!] (Internal Report No. 30). Fribourg: University of Fribourg.

. (1984). "Asking how to act." Archives de Psychologie, 52, 103-120.

Flammer, A., H. Kaiser, \& R. Lüthi. (1981). Gewusst Wie - Gefragt Wie [Known how - Asked how] (Internal Report No. 27). Fribourg: University of Fribourg.

Flammer, A., H. Kaiser, \& P. Müller-Bouquet. (1981). "Predicting what questions people ask." Psychological Research, 43, 421-429.

Fuhrer, U. (1989). Cognitive and social goals of question asking: Knowledge acquisition under impression management concerns. Unpublished manuscript. University of Bern. Bern, Schweitz.

Galambos, J.A. \& J.B. Black. (1985). "Using knowledge of activities to understand and answer questions." Pp. 157-189 in The psychology of questions, edited by A.C. Graesser \& J.B. Black. Hillsdale, NJ: Erlbaum. 
Garner, R., P.A. Alexander, M.G. Gillingham, J.M. Kulikowich, \& R. Brown. (1991). "Interest and learning from text." American Educational Research Journal, 28, 3, 643-659.

Getzels, J.W. (1982). "The problem of the problem." Pp. 37-49 in New directions for methodology of social and behavioral science: Question framing and response consistency, edited by R. Hogarth. San Francisco: Jossey Bass.

- (1988). "Problem finding and creative thought." Questioning Exchange, 2(2), 95103.

Gibbs, R.W., R.A.G. Mueller, R.W. Cox. (1988). "Common ground in asking and understanding questions." Language and Speech, 31, 321-335.

Good, T.L., R.L. Slavings, K. Hobson Harel, \& H. Emerson. (1987). “Student passivity: a study of question asking in K-12 classrooms." Sociology of Education, 60, 181-199.

Good, T.L., R.L. Slavings, \& D.A. Mason. (1988). "Learning to ask questions: grade and school effects." Teaching \& Teacher Education, 4, 363-378.

Graesser, A.C. \& D. Demphill. (1991). "Question answering in the context of scientific mechanisms." Journal of Memory and Language, 30, 186-209.

Graesser, A.C. \& T. Murachver. (1985). "Symbolic procedures of question answering." Pp. 15-88 in The psychology of questions, edited by A.C. Graesser \& J.B. Black. Hillsdale, NJ: Lawrence Erlbaum.

Graesser, A.C., P.J. Byrne, \& M.L. Behrens. (1992). "Answering questions about information in databases." Pp. 229-252 in Questions and information systems, edited by T.W. Lauer, E. Peacock, \& A.C. Graesser. Hillsdale, NJ: Lawrence Erlbaum.

Grice, H.P. (1975). "Logic and conversation." Pp. 41-59 in Syntax and semantics, (Vol. 3), edited by P. Cole \& J.L. Morgan. New York: Seminar Press.

Guthrie, J.T. \& M.J. Dreher. (1990). "Literacy as search: explorations via computer." Pp. 65-113 in Cognition, education, and multimedia: Exploring ideas in high technology, edited by D. Nix, \& S. Spiro. Hillsdale, NJ: Lawrence Erlbaum.

Harrah, D. (1984). "The logic of questions." Pp. 715-764 in Handbook of Philosophical Logic (Vol. 2), edited by D. Gabbay \& F. Guenthner. Dordrecht, the Netherlands: Reidel.

Hartley, J.R., \& M.J. Smith. (1988). "Question answering and explanation giving in online help systems." Pp. 338-360 in Artificial intelligence and human learning, edited by J. Self. London: Chapman and Hall.

Isaacs, N. (1930). "Children's why questions." Pp. 291-349 in Intellectual growth in children, edited by S. Isaacs. London: Routledge and Kegan Paul.

Karabenick, S.A. (1991, June). Class differences in perceived teacher support related to the likelihood of student classroom questioning. Paper presented at the Annual Convention of the American Psychological Association (APA), Washington, DC.

Karabenick, S.A. \& T.R. Knapp. (1988). "Help-seeking and the need for academic assistance." Journal of Educational Psychology, 80, 406-408.

Karabenick, S.A. \& R. Sharma. (1991, April). Student classroom questioning: Its relation to motivation, learning strategy use and perceived teacher support. Paper presented at the American Educational Research Association (AERA), Chicago.

Kato, T. (1986). "What question-asking protocols can say about the user interface." International Journal of Man-Machine Studies, 25, 659-673.

King, A. (1992). "Facilitating elaborative learning through guided student-generated questioning." Educational Psychologist, 27, 111-126.

Lang, K.L., A.C. Graesser, S.T. Dumais, \& D. Kilman. (1992). "Question asking in human-computer interfaces." Pp. 131-166 in Questions and information systems, edited by T.W. Lauer, E. Peacock, \& A.C. Graesser. Hillsdale, NJ: Lawrence Erlbaum.

Lehnert, W.G. (1978). The process of question answering. Hillsdale, NJ: Lawrence Erlbaum. 
Letovksy, S. (1986). "Cognitive processes in program comprehension." Pp. 58-79 in Empirical studies of programmers, edited by E. Soloway \& S. Iyengar. Norwood, NJ: Ablex.

Markman, E.M. (1979). "Realizing that you don't understand: elementary school children's awareness of inconsistencies." Child Development, 50, 643-655.

Miyake, N. (1986). "Constructive interaction and the iterative process of understanding." Cognitive Science, 10, 151-177.

Miyake, N., \& D.A. Norman. (1979). "To ask a question one must know enough to know what is not known." Journal of Verbal Learning and Verbal Behavior, 18, 357-364.

Mosher, F.A. \& J.R. Hornsby. (1968). "On asking questions." Pp. 86-102 in Studies in cognitive growth, edited by J.S. Bruner, R.R. Olver \& P.M. Greenfield. New York: Wiley.

Nadler, A. (1983). "Personal characteristics and help-seeking." Pp. 303-336 in New directions in helping: Help-seeking (Vol. 2), edited by B. DePaulo, A. Nadler \& J. Fisher. New York: Academic Press.

Nelson-LeGall, S. (1981). "Help-seeking: An understudied problem-solving skill in children." Developmental Review, 1, 224-226. . (1985). "Help-seeking behavior in learning." Pp. 55-90 in Review of Research in Education, edited by E.W. Gordon. Washington: American Research Association.

Nelson-LeGall, S. \& S. Glor-Scheib. (1985). "Help-seeking in elementary classrooms: An observational study." Contemporary Educational Psychology, 10, 58-71.

Newman, R. S. (1992). "Goals and self-regulated learning: What motivates children to seek academic help?" Pp. 151-183 in Advances in motivation and achievement: Goals and self-regulatory processes (Vol. 7), edited by M.L. Maehr \& P.R. Pintrich. Greenwich, CT: JAI Press.

Newman, R.S. \& L. Goldin. (1990). "Children's reluctance to seek help with schoolwork." Journal of Educational Psychology, 82, 92-100.

Paradice, D.B. (1992). "A question theoretic analysis of problem formulation: Implications for computer-based support." Pp. 287-302 in Questions and information systems, edited by T.W. Lauer, E. Peacock, \& A.C. Graesser. Hillsdale, NJ: Lawrence Erlbaum.

Piaget, J. (1959). The language and thought of the child (reprint of 1929). London: Routledge.

Pilkington, R.M. (1992). "Question-answering for intelligent on-line help: The process of intelligent responding," Cognitive Science, 16, 455-489.

Pressley, M. \& D. Forrest-Pressley. (1985). "Questions and children's cognitive processing." Pp. 277-296 in The psychology of questions, edited by A.C. Graesser \& J.B. Black. Hillsdale, NJ: Lawrence Erlbaum.

Reder, L.M. (1987). "Strategy selection in question answering." Cognitive Psychology, 19, 90-138.

Rescher, N. (1982). Empirical inquiry. London: Athlone Press.

Robertson, S.P. (1993). TSUNAMI: Simultaneous understanding, answering and memory interaction for questions. (Research Report NO.18790). Yorktown Heights, NY: IBM.

Robertson, S.P., J.B. Black, \& W.G. Lehnert (1985). "Misleading question effects as evidence for integrated question understanding and memory search." Pp. 191-218 in The psychology of questions, edited by A.C. Graesser \& J.B. Black. Hillsdale, NJ: Lawrence Erlbaum.

Rohertson, S. \& M. Swartz. (1988). "Why do we ask ourselves questions?" Questioning Exchange, 2, 47-51.

Robertson, S.P., K. Weber, J.D. Ullman, \& A. Mehta. (1993). “Parallel question parsing and memory retrieval." Journal of Memory and Language, 32, 155-168.

Rosenshine, B. \& S. Chapman. (1992, April). Teaching students to generate questions: A 
review of research on the effectiveness of different concrete prompts. Paper presented at the Annual Meeting of the (AERA), San Francisco, CA.

Ross, H.S. \& R.H. Balzer. (1975). "Determinants and consequences of children's questions." Child Development, 46, 536-539.

Ross, H.S. \&. J.C. Killey. (1977). "The effect of questioning on retention." Child Development, $48,312-314$.

Scardamalia, M. \& C. Bereiter. (1991). "Higher levels of agency for children in knowledge building: A challenge for the design of new knowledge media." The Journal of the Learning Sciences, 1, 37-68.

- (1992). "Text-based and knowledge-based questioning by children." Cognition and Instruction, 9, 177-199.

- (1993). "Technologies for knowledge-building discourse." Communications of the $A C M, 36(5), 37-41$.

Schank, R.C. (1993). "Learning via multimedia computers." Communications of the ACM, $36(5), 54-56$.

Schouten, A. \& J. Zwijnenburg. (1987). Zelfbell en vragen stellen [Self-esteem and question asking]. Unpublished master's thesis, Leiden University, Leiden, the Netherlands.

Schraagen, J.M. (1993). "How experts solve a novel problem in experimental design." Cognitive Science, 17, 285-309.

Shell, R.M. \& N. Eisenberg. (1992). "A developmental model of recipients" reaction to aid." Psychological Bulletin, 111, 413-433.

Siegler, R.S. (1977). "The twenty questions game as a form of problem solving." Child Development, 48, 395-403.

Smith, K.H., T.A. Tykodi, \& B.T. Mynatt. (1988). "Can we predict the form and function of spontaneous questions?" Questioning Exchange, 2, 53-60.

Subotnik, R.F. \& T. Moore. (1988). "Literature on problem finding." Questioning Exchange, $2,87-93$.

Suchman, J.R. (1961). "Inquiry training: Building skills for autonomous discovery." Merrill Palmer Quarterly, 147-169.

Tizard, B. \& M. Hughes. (1984). Young children learning: talking and thinking at home and at school. Cambridge, MS: Harvard University Press.

Van der Meij, H. (1986). Questioning: A study on the questioning behavior of elementary school children. Den Haag, The Netherlands: SVO.

- (1987). "Assumptions of information-seeking questions." Questioning Exchange, 1, $111-117$.

- (1988). "Constraints on question-asking in classrooms." Journal of Educational Psychology, 80, 401-405.

- (1989). The role of self-esteem on question raising and question posing. Internal Report 1 , University of Leiden, the Netherlands.

- (1990a). "Effects of prior knowledge on question asking." Zeitschrift für Pädagogische Psychologie, 4, 87-96.

. (1990b). "Question asking: to know that you don't know is not enough." Journal of Educational Psychology, 82, 505--512.

- (1990c). "An experimental study of the when and what of children's questions." Tijdschrift woor Onderwijsresearch, 15, 162-171.

. (1991). "General problems of questioning research." Psychological Research, 53, 315-318.

. (1992, April). A critique of research on questioning. Paper presented at the Annu- 
al Meeting of the American Educational Research Association (AERA), San Francisco, CA (ED 343.950).

. (1993). "What's the title? A case study of questioning in reading." Journal of Research in Reading, 16, 46-56.

Van der Meij, H., C. Baarends, \& G. Leijh. (1988). Effects of self-esteem on questioning. Internal Report 2, University of Leiden, the Netherlands.

Van der Meij, H. \& J.T. Dillon. (in press). "Adaptive student questioning." Joumal of Experimental Education.

Van der Meij, H., M. Meer, \& M. Ponte. (1989). "Vragen stellen op de LOM-school [Questioning in special education]." Nederlands Tijdschrift voor Opvoeding, Vorming en Onderwijs, 5, 279-287.

Van Zee, E.H. \& J. Minstrell. (1991). Using questioning to guide student thinking. Paper presented at the 1991 American Educational Research Association, Chicago.

- (1993). Reflective discourse: Developing shared understanding in a physics classroom. Unpublished manuscript. University of California, Graduate School of Education, California.

Vygotskij, L.S. (1962). Thought and language. Cambridge, MS: MIT Press.

Yussen, S.R., A.D. Stright, \& B. Payne. (1993). "Where is it? Searching for information in a college textbook." Contemporary Educational Psychology, 18, 240-257.

Woloshyn, V.E., M. Pressley, \& W. Schneider. (1992). "Elaborative-interrogation and prior knowledge effects on learning of facts." Journal of Educational Psychology, 84, 115-124.

Wong, B.Y.L. (1985). "Self-questioning instructional research: a review." Review of Educational Research, 55, 227-268. 